“(C) 2011 IEEE. Personal use of this material is permitted. Permission from IEEE must be obtained for all other uses, in any current or future media, including reprinting/republishing this material for advertising or promotional purposes, creating new collective works, for resale or redistribution to servers or lists, or reuse of any copyrighted component of this work in other works." 


\title{
Evaluation of A Class of Improved DTC Method Applied in DFIG For Wind Energy Applications
}

\author{
Yongchang Zhang*†, Zhengxi $\mathrm{Li}^{*}$, Tianshi Wang ${ }^{\dagger}$, Wei $\mathrm{Xu}^{\dagger}$, Jianguo Zhu ${ }^{\dagger}$ \\ *Inverter Technologies Engineering Research Center of Beijing, North China University of Technology, Beijing, China \\ ${ }^{\dagger}$ Faculty of Engineering and Information Technology, University of Technology Sydney, NSW 2007, Australia \\ Email: yozhang@ieee.org
}

\begin{abstract}
Large torque ripple and variable switching frequency are the two most notable drawbacks of conventional switching table based direct torque control (DTC) for doubly fed induction generator (DFIG). By using one active vector and one null vector during one control cycle, the torque ripple can be significantly reduced while achieving almost constant switching frequency. This paper propose a very simple but effective method to obtain the duty ratio of the active vector, which is able to reduce the complexity and improve the system robustness while reducing both torque and flux ripples. Furthermore, this paper points that by appropriately arranging the sequence of active vector and null vector, the switching frequency can be further reduced and the performance is only slightly affected. This fact is useful for high power wind energy applications with restricted switching frequency. The developed method is compared with one of the prior analytical methods based on torque ripple RMS minimization and exhibits lower rotor flux ripple and better harmonic performance of stator and rotor currents. The presented simulation results obtained from a 15 kW DFIG validates its effectiveness.
\end{abstract}

\section{INTRODUCTION}

Wind energy is the fastest developing renewable energy resource around the world and it has evolved from early fixedspeed wind turbine system into modern variable speed constant frequency (VSCF) system [1]. Wind turbine system based on doubly fed induction generator (DFIG) is one of the most popular configurations because it provides decoupled control of active power and reactive power. Furthermore, the VA rating of converter is only a fractional part of that of the feeding machine, usually $25 \% \sim 30 \%$, depending on the operating speed range [2].

Conventional control of DFIG-based wind turbine system is based on stator flux oriented control, with rotor current control as the internal loop [3]. Although the orientation based vector control can achieve decoupling between $d$-axis and q-axis current, it introduces rotary transformation and relies much on the accuracy of machine parameters. Furthermore, the structure of multiple loop system needs much tuning effort to ensure system stability over the whole speed range [4].

Recently direct torque control (DTC) have been developed for DFIG [5]. The basic principle of DTC is selecting an appropriate voltage vector from a switching table to restrict both torque and flux errors in their respective hysteresis bands. Compared to prior stator flux/voltage orientation control, DTC is characterized by quick dynamic response, simple structure and low parameter dependency, so it has become an interest of research throughout the world. Despite the merits above, DTC has some notable drawbacks, including variable switching frequency and irregular torque and flux ripples at steady state, especially at low speeds.

To improve the steady state performance of DTC and maintain fixed switching frequency, many methods have been proposed in the literature and SVM-DTC is a kind of very popular approach [6]. Although better performance was obtained, the complexity of system was increased and more machine parameters were needed. Apart from the SVM-based methods, predictive DTC was also proposed to improve the steady performance [7]-[9]. Different from conventional DTC, the predictive DTC employs two vectors to eliminate the torque and flux errors, where the active vector is selected from the switching table in conventional DTC and usually followed by a null vector [7]-[9]. The duty ratio of the active vector is determined according to various principles, including torque ripple minimization [7], fuzzy logic adaptation [8], equalizing the mean torque with the reference value over one cycle [9], etc. Despite the merits of enhanced dynamic response and better steady state performance, the developed predictive DTC so far relies much on the mathematical model and machine parameters. Recently, the authors proposed a novel method to eliminate the parameter dependence for duty based DTC, which has been successfully applied in PMSM DTC drives [10]. This paper will make a further step to the previous work in [10] by extending the novel method to the DTC of DFIG for wind energy applications.

The structure of this paper is organized as follows. After introducing the model of DFIG and analyzing the influences of rotor voltage vectors on both torque and rotor flux in Section II, the principle of duty based DTC will be presented in Section III by comparing the novel method with prior torque ripple RMS minimization method. The way to reduce the switching frequency for duty DTC is also presented in Section III. Section IV shows the simulation results obtained from a $15 \mathrm{~kW}$ DFIG system. The conclusion is drawn in Section V.

\section{Model OF DFIG}

\section{A. Machine Equations}

A mathematical model of a DFIG described by space vectors in an arbitrary frame with a rotating speed of $\omega_{k}$ is 
expressed as:

$$
\begin{aligned}
\boldsymbol{u}_{s} & =R_{s} \boldsymbol{i}_{s}+\frac{d \boldsymbol{\psi}_{s}}{d t}+j \omega_{k} \boldsymbol{\psi}_{s} \\
\boldsymbol{u}_{r} & =R_{r} \boldsymbol{i}_{r}+\frac{d \boldsymbol{\psi}_{r}}{d t}+j\left(\omega_{k}-\omega_{r}\right) \boldsymbol{\psi}_{r} \\
\boldsymbol{\psi}_{s} & =L_{s} \boldsymbol{i}_{s}+L_{m} \boldsymbol{i}_{r} \\
\boldsymbol{\psi}_{r} & =L_{m} \boldsymbol{i}_{s}+L_{r} \boldsymbol{i}_{r} \\
T_{e} & =\frac{3}{2} p \lambda L_{m}\left(\boldsymbol{\psi}_{r} \otimes \boldsymbol{\psi}_{s}\right)
\end{aligned}
$$

where $\boldsymbol{u}_{\boldsymbol{s}}, \boldsymbol{i}_{s}, \boldsymbol{u}_{r}, \boldsymbol{i}_{r}, \boldsymbol{\psi}_{s}$ and $\boldsymbol{\psi}_{r}$ are the stator voltage vector, stator current vector, rotor voltage vector, rotor current vector, stator flux linkage vector and rotor flux linkage vector, respectively; $R_{s}, R_{r}, L_{s}, L_{r}$ and $L_{m}$ are the stator resistance, rotor resistance, stator inductance, rotor inductance and mutual inductance, respectively; $\omega_{r}$ and $p$ are the electrical rotor speed and pole pairs and $\lambda=1 /\left(L_{s} L_{r}-L_{m}^{2}\right)$.

\section{B. Effects of Voltage Vectors on Torque and Flux}

From (1) to (4), the model of DFIG can be expressed in stationary frame $\left(\omega_{k}=0\right)$ with $\psi_{s}$ and $\psi_{r}$ as state variables:

$$
\begin{aligned}
\frac{d \boldsymbol{\psi}_{s}}{d t} & =-\lambda L_{r} R_{s} \boldsymbol{\psi}_{s}+\lambda L_{m} R_{s} \boldsymbol{\psi}_{r}+\boldsymbol{u}_{s} \\
\frac{d \boldsymbol{\psi}_{r}}{d t} & =\lambda L_{m} R_{r} \boldsymbol{\psi}_{s}-\left(\lambda L_{s} R_{r}-j \omega_{r}\right) \boldsymbol{\psi}_{r}+\boldsymbol{u}_{r}
\end{aligned}
$$

The differentiation of $T_{e}$ with respect to time $t$ can be obtained from (5), (6) and (7) as

$$
\begin{aligned}
\frac{d T_{e}}{d t}= & \frac{3}{2} p \lambda L_{m}\left[-\lambda\left(L_{s} R_{r}+L_{r} R_{s}\right) \operatorname{Im}\left(\boldsymbol{\psi}_{r}^{*} \boldsymbol{\psi}_{s}\right)\right. \\
& \left.-\omega_{r} \operatorname{Re}\left(\boldsymbol{\psi}_{r}^{*} \boldsymbol{\psi}_{s}\right)+\operatorname{Im}\left(\boldsymbol{u}_{r}^{*} \boldsymbol{\psi}_{s}\right)+\operatorname{Im}\left(\boldsymbol{\psi}_{r}^{*} \boldsymbol{u}_{s}\right)\right]
\end{aligned}
$$

Similarly, the differentiation of $\left|\psi_{r}\right|$ with respect to time $t$ can be obtained from (7) as

$$
\begin{aligned}
\frac{d\left|\boldsymbol{\psi}_{r}\right|}{d t}= & \frac{1}{\left|\boldsymbol{\psi}_{r}\right|}\left[\lambda L_{m} R_{r} \operatorname{Re}\left(\boldsymbol{\psi}_{r}^{*} \boldsymbol{\psi}_{s}\right)\right. \\
& \left.-\lambda L_{s} R_{r}\left|\boldsymbol{\psi}_{r}\right|^{2}+\operatorname{Re}\left(\boldsymbol{\psi}_{r}^{*} \boldsymbol{u}_{r}\right)\right]
\end{aligned}
$$

The influences of rotor voltage vectors on torque and rotor flux can be obtained from (8) and (9). Figs. 1 and 2 graphically illustrate the evolutions of torque and rotor flux slopes versus time at sub-synchronous speed and hyper-synchronous speed for a specific $8.5 \mathrm{~kW}$ DFIG, respectively. The information of sector, shown in the bottom of Figs. 1 and 2, is obtained from the position of rotor flux. The sector division for DTC of DFIG is shown in Fig. 3 in rotor coordinate, where sub-synchronous rotor speed is assumed.

The null rotor voltage vector will lead to negative slope for rotor flux. However, the value is so small compared to the other non-null vectors that it can be said that the null vector will only stall the rotor flux without affecting its amplitude. It should be noted that the influence of null vector on torque is different for sub-synchronous speed and hyper-synchronous speed. The influences of a null rotor voltage vector on torque and rotor flux are shown in Tab. I.
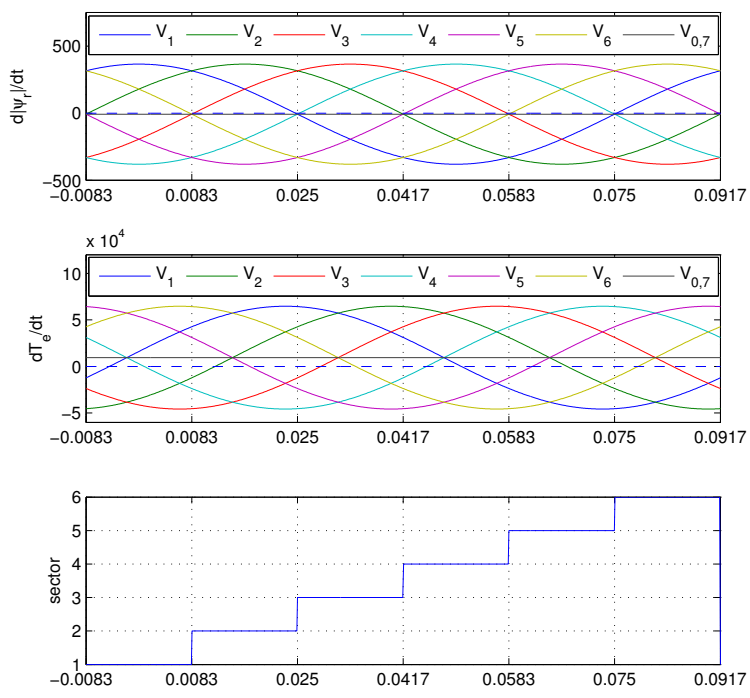

Fig. 1. Torque and flux slopes versus time at sub-synchronous speed
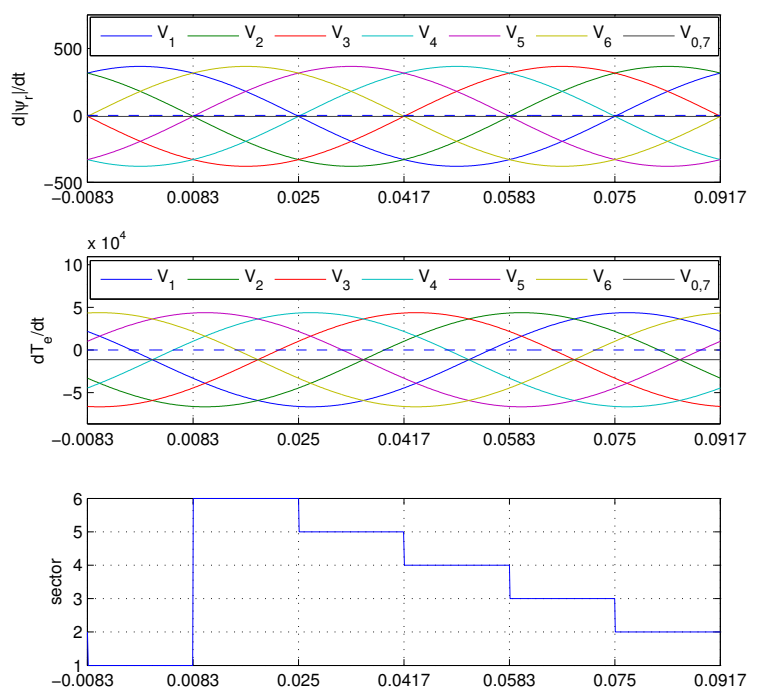

Fig. 2. Torque and flux slopes versus time at hyper-synchronous speed.

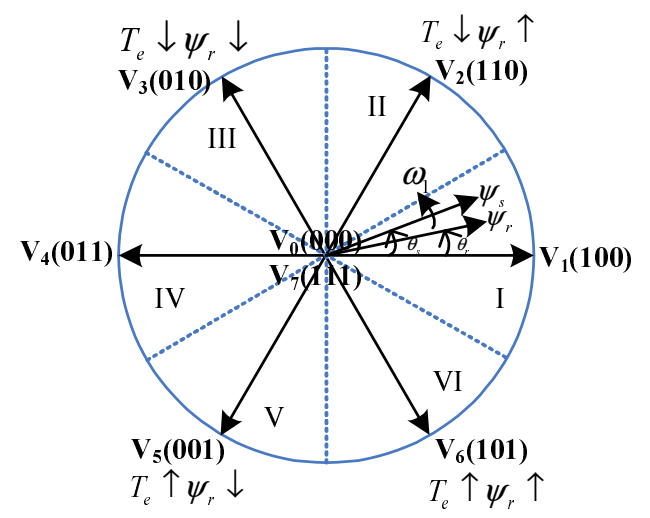

Fig. 3. Sector division for DTC of DFIG

Although conventional DTC does not employ the null vector 
TABLE I

EFFECTS OF NULL VOLTAGE VECTOR ON TORQUE AND FLUX

\begin{tabular}{cccc}
\hline \multicolumn{2}{c}{ mode } & $T_{e}$ & $\boldsymbol{\psi}_{r}$ \\
\hline motor & sub & $\uparrow$ & $=$ \\
motor & hyper & $\downarrow$ & $=$ \\
generator & sub & $\uparrow$ & $=$ \\
generator & hyper & $\downarrow$ & $=$ \\
\hline
\end{tabular}

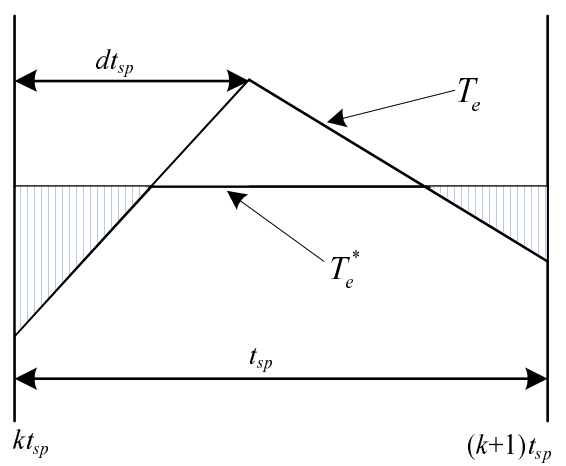

Fig. 4. Typical waveform of torque when both active vector and null vector are employed during one period.

to avoid possible increased complexity in the switching table [5], they fail to make full use of the ability of null vector in reducing torque and flux ripples. As shown in Figs. 1 and 2 , the null rotor voltage vector produces very small changes in the torque and flux slopes, so it is possible to incorporate the null vector to improve the steady state performance of conventional DTC.

\section{Comparative Study OF Duty Based DTC}

\section{A. Model Based Duty Determinations}

Suppose the torque slopes for the active vector and the null vector are $s_{1}$ and $s_{2}$, respectively, which can be obtained from (8). A typical waveform of torque in one control period $t_{s p}$ is shown in Fig. 4.

So far, there are several kinds of methods to determine the optimal duty ratio $d$ of the active vector. One of the popular methods is based on the principle of torque ripple minimization, which was firstly proposed in 1999 for IM DTC [7]. The principle can be expressed as

$$
\frac{1}{t_{s p}} \int_{k t_{s p}}^{(k+1) t_{s p}}\left(T_{e}-T_{e}^{*}\right)^{2} d t \rightarrow \min .
$$

Solving the equation (10) will lead to

$$
d=\frac{2\left(T_{e}^{*}-T_{0}\right)-s_{2} t_{s p}}{\left(2 s_{1}-s_{2}\right) t_{s p}}
$$

The method in (11) is model dependent and require lots of machine parameters, which is caused by the torque slope calculation in (8).

\section{B. Novel method of duty determination}

Apart from the comparative study of the prior three methods, this paper will propose a novel method, which is simple but very effective in reducing both torque and flux ripples. The main difference between this novel method and prior methods is that it has very simple expression and eliminates the machine parameter dependence, hence increasing the robustness of system. The proposed method to obtain the optimal duty ratio is expressed as

$$
d=\left|\frac{E_{T}}{C_{T}}\right|+\left|\frac{E_{\psi}}{C_{\psi}}\right|=\left|\frac{T_{e}^{*}-T_{0}}{C_{T}}\right|+\left|\frac{\psi_{r}^{*}-\psi_{0}}{C_{\psi}}\right|
$$

where $\psi_{0}$ is the rotor flux at the $k t h$ sampling instant; $C_{T}$ and $C_{\psi}$ are two positive constants. The connection between this method and prior method can be simply explained as follows. The method in (11) can be rewritten as

$$
d=\frac{2\left(T_{e}^{*}-T_{0}\right)}{\left(2 s_{1}-s_{2}\right) t_{s p}}+\frac{-s_{2}}{2 s_{1}-s_{2}}
$$

which is composed of two components. The first item is proportional to torque error, which is generally reduced by the active vector obtained from the switching table. The second one is proportional to the torque slope $s_{2}$ caused by a null vector. As a null vector will cause drop in the rotor flux, it is reasonable to connect the second item to the rotor flux control. By replacing the parameter dependent denominators in (13) by constants, a novel method eliminating the parameter dependence can be obtained, as shown in (12).

To make the novel method practical, this paper also presents the guideline for tuning $C_{T}$ and $C_{\psi}$. It is found that in a wide range, the variation of $C_{T}$ and $C_{\psi}$ do not cause much performance differences, especially for $C_{\psi}$. The influence caused by the variation of $C_{\psi}$ is relatively small compared to the variation of $C_{T}$. If $C_{T}$ is too big, although the rotor flux is well controlled, there is steady state error in the torque and the dynamic performance is deteriorated. Too small value of $C_{T}$ will lead to better dynamic response at the cost of deteriorating the steady state performance. In general, the tuning of $C_{T}$ and $C_{\psi}$ is a trade-off between dynamic response and steady state performance. Extensive simulations indicate that the appropriate range of $C_{T}$ is $10 \%$ 30\% rated torque while $C_{\psi}$ can be variable in the range of $10 \% \sim 100 \%$ rated stator flux. The rated torque can be easily obtained from the machine nameplate and the rated stator flux can be obtained as $\psi_{b}=U_{b} / \omega_{b}$, where $U_{b}$ and $\omega_{b}$ are the base value of phase voltage and rotor speed.

\section{Switching Frequency Reduction in Duty Based DTC}

For high power wind energy applications, reducing switching frequency is very important due to the limitations of the high power semiconductors. In this section, this paper will exploit the ability of duty based DTC methods in reducing switching frequency while maintaining the control performance. The key point is exchanging the sequence of active vector and null vector appropriately. In prior methods [7][9], it is assumed that the active vector will be firstly applied over the duration decided by (11) and (12), and then switched to an appropriate null vector for the rest time of the period. The appropriate null vector means that vectors "100", "010" and "001" will be followed by " 000 " while other vectors 


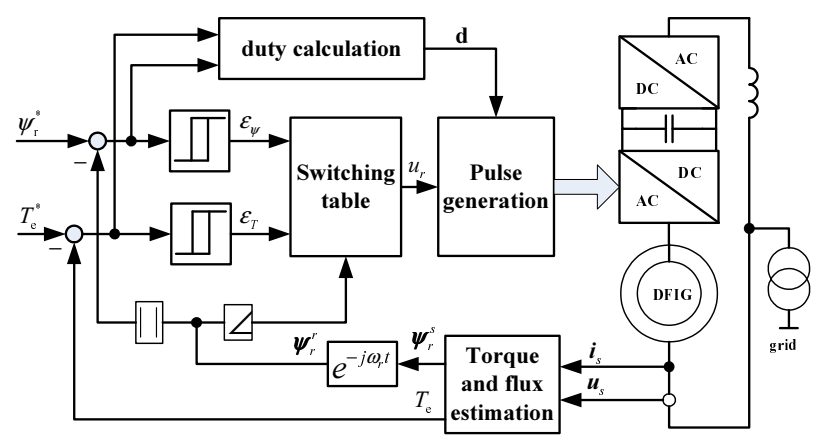

Fig. 5. Control diagram of the novel duty DTC for a DFIG system

TABLE II

CONTROL AND MACHINE PARAMETERS

\begin{tabular}{lcr}
\hline DC-bus voltage [V] & $V_{d c}$ & 500 \\
Rated motor power [kW] & $P_{N}$ & 15 \\
Rated motor voltage [V] & $U_{N}$ & 380 \\
Rated (Based) motor frequency [Hz] & $f_{N}$ & 50 \\
Number of motor pairs & $N_{p}$ & 2 \\
Motor stator resistance $[\Omega]$ & $R_{s}$ & 0.168 \\
Motor rotor resistance $[\Omega]$ & $R_{r}$ & 0.199 \\
Motor mutual inductance $[\mathrm{H}]$ & $L_{m}$ & 0.050 \\
Motor stator inductance $[\mathrm{H}]$ & $L_{s}$ & 0.050 \\
Motor rotor inductance $[\mathrm{H}]$ & $L_{r}$ & 0.045 \\
\hline
\end{tabular}

followed by "111". In fact, the switching frequency can be further reduced if the sequence of the active vector and the null vector is decided by the switching state of the vector at the end of the last cycle. For example, if the vectors during the last cycle are "100" and "000" with "000" at the end, and the vectors to be applied in the next cycle are "001" and "000", in that case, "000" instead of "001" will be applied firstly to decrease the switching frequency.

\section{Simulation Results}

To evaluate the performances of various duty-based DTC methods and verify the effectiveness of the proposed method, simulations are carried out in the environment of Matlab/Simulink. The control diagram of the novel duty DTC for a DFIG system is shown in Fig. 5, where the duty calculation is obtained from (12). For the ripple RMS minimization method, the duty calculation is replaced by (11). To obtain similar switching frequency for these two methods, the sampling frequency is $5 \mathrm{kHz}$ for the ripple minimization method and $4.8 \mathrm{kHz}$ for the novel method. The machine parameters of DFIG is shown in Tab. II.

\section{A. Comparative Studies}

The torque ripple RMS minimization DTC and the novel DTC are comparatively simulated in this part to evaluate their respective performance. The rotor speed is fixed at $80 \%$ synchronous speed $(1200 \mathrm{r} / \mathrm{min})$. The two positive constants in (12) for the proposed method are $C_{T}=0.15 T_{b}$ and $C_{\psi}=0.5 \psi_{b}$.

Figs. 6 and 7 present the simulation results during step changes of torque and rotor flux for torque ripple RMS
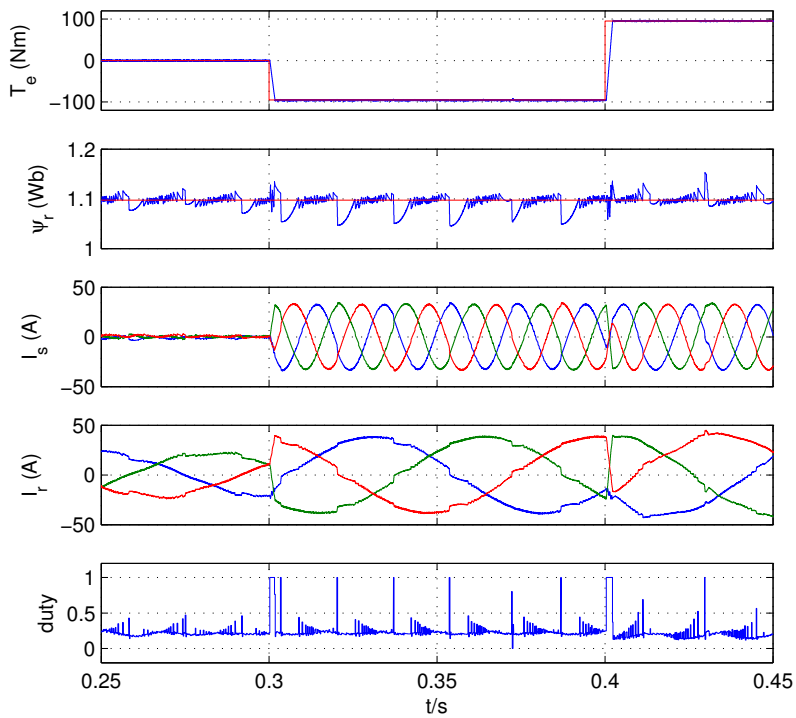

Fig. 6. Simulation results of prior RMS ripple minimization DTC with step changes of torque and rotor flux

TABLE III

STEADY RESPONSES OF THE TWO DUTY BASED DTC METHODS

\begin{tabular}{ccccccc}
\hline method & $\begin{array}{c}f_{s} \\
(\mathrm{~Hz})\end{array}$ & $\begin{array}{l}f_{a v} \\
(\mathrm{~Hz})\end{array}$ & $\psi_{\text {rip }}(\mathrm{Wb})$ & $T_{\text {rip }}(\mathrm{Nm})$ & $\begin{array}{c}\text { THD } \\
\text { of } \boldsymbol{i}_{s}\end{array}$ & $\begin{array}{c}\text { THD } \\
\text { of } \boldsymbol{i}_{r}\end{array}$ \\
\hline $\begin{array}{c}\text { method I } \\
\text { using (11) }\end{array}$ & $5 \mathrm{k}$ & $2.02 \mathrm{k}$ & 0.0105 & 0.764 & $2.04 \%$ & $3.10 \%$ \\
\hline $\begin{array}{c}\text { method II } \\
\text { using (12) }\end{array}$ & $4.8 \mathrm{k}$ & $2.03 \mathrm{k}$ & 0.0056 & 1.0562 & $1.35 \%$ & $1.83 \%$ \\
\hline
\end{tabular}

minimization DTC and the novel DTC, respectively. From top to bottom, the curves shown in Figs. 6 and 7 are real and commanding torque, real and commanding rotor flux, three phase stator currents, three phase rotor currents and the duty of the active vector, respectively. As shown in Fig. 6, the torque steps from zero to $-1 \mathrm{pu}$ (generation) at $\mathrm{t}=0.3 \mathrm{~s}$ and then steps from $-1 \mathrm{pu}$ to $1 \mathrm{pu}$ at $\mathrm{t}=0.4 \mathrm{~s}$ (motoring). The rotor flux is kept constant at $1.0974 \mathrm{~Wb}$. It is clearly seen that for the ripple minimization method, there is obvious oscillation in the rotor flux. On the contrary, the oscillation in rotor flux is significantly reduced for the novel method. Consequently, the rotor current of the novel method is also more sinusoidal than that of ripple minimization method. The dynamic performance of the novel method is also better than that of torque ripple minimization method, as shown in Fig. 8.

The quantitative comparison of these two duty based DTC methods under the steady state condition of $95.4930 \mathrm{Nm}$ and $1.0974 \mathrm{~Wb}$ at $0.8 \mathrm{pu}$ synchronous speed $(\mathrm{t}>0.4 \mathrm{~s})$ are summarized in Tab. III, including sampling frequency $f_{s}$, average switching frequency $f_{a v}$, torque ripple $T_{\text {rip }}$, flux ripple $\psi_{\text {rip }}$, THDs of stator current $\boldsymbol{i}_{s}$ and rotor current $\boldsymbol{i}_{r}$ (calculated up to $6000 \mathrm{~Hz}$ harmonics). It is seen from Tab. III that the torque ripple of the novel method is slightly bigger than that of the ripple minimization method, but the flux ripple is much smaller, which leads to better performance in terms of THDs of stator and rotor currents. The harmonic spectra of rotor 

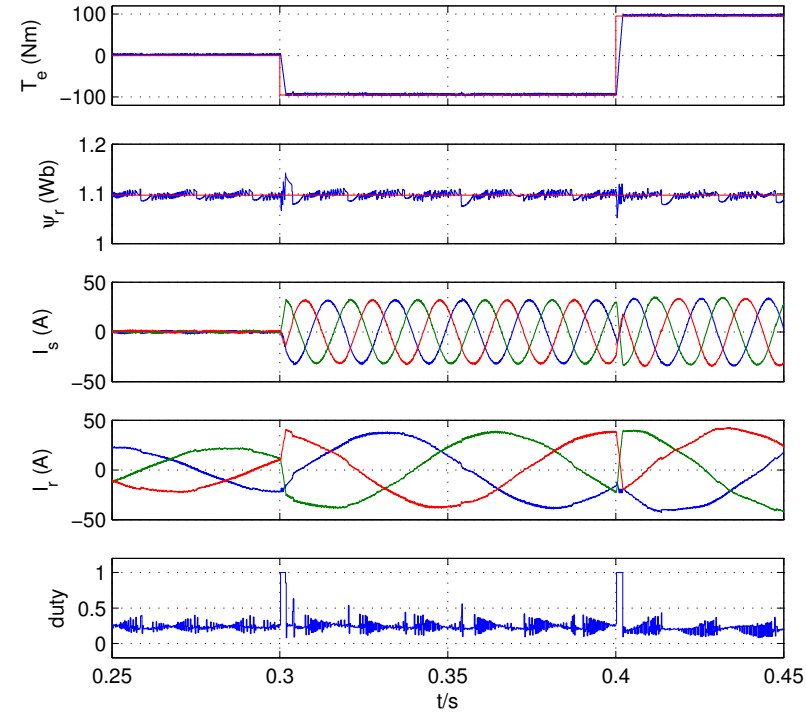

Fig. 7. Simulation results of the novel DTC method with step changes of torque and rotor flux

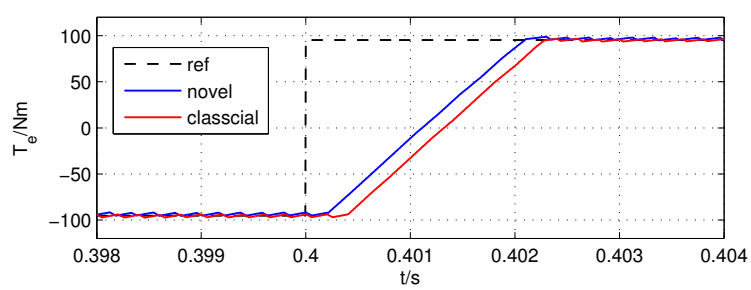

Fig. 8. Zoomed torque responses from -1 pu to 1 pu for the two duty based DTC methods
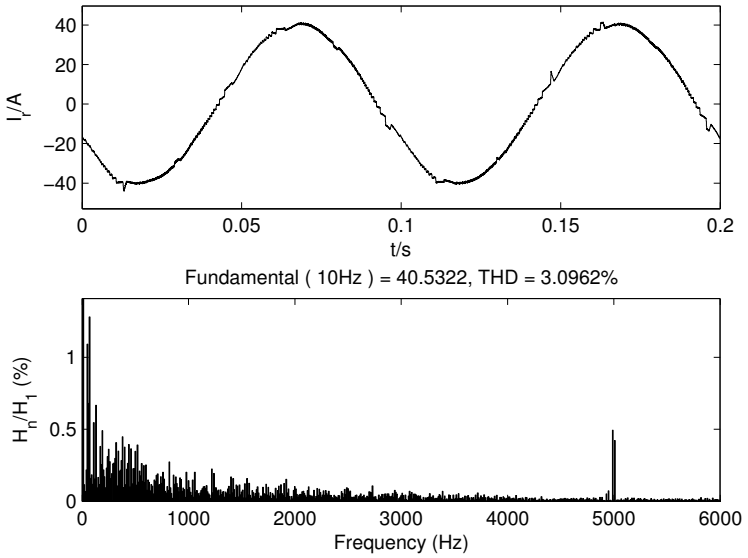

Fig. 9. Harmonic spectrum of rotor current using using RMS ripple minimization DTC

current for these two methods are presented in Figs. 9 and 10.

\section{B. Switching frequency reduction}

Fig. 11 presents the simulation results of the novel DTC considering switching frequency reduction. The average switching frequency is reduced up to $29 \%$, from $2.03 \mathrm{kHz}$ in Fig. 7 to $1.44 \mathrm{kHz}$ in Fig. 11, while the THDs of stator
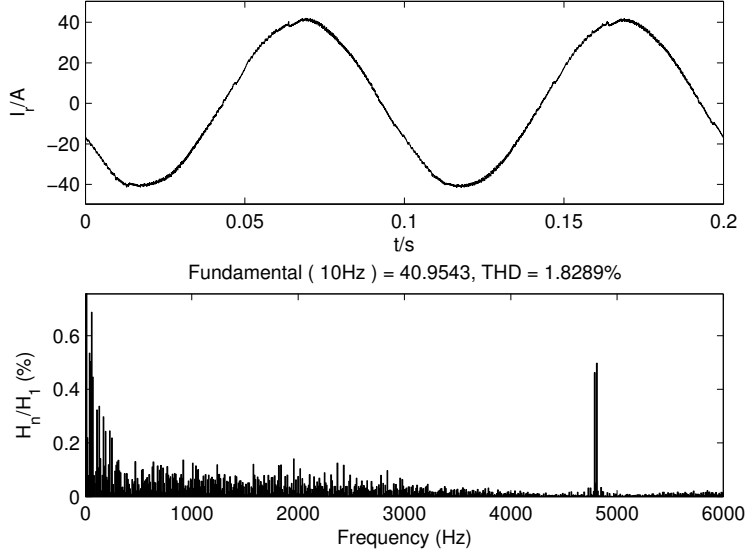

Fig. 10. Harmonic spectrum of rotor current using the novel DTC.
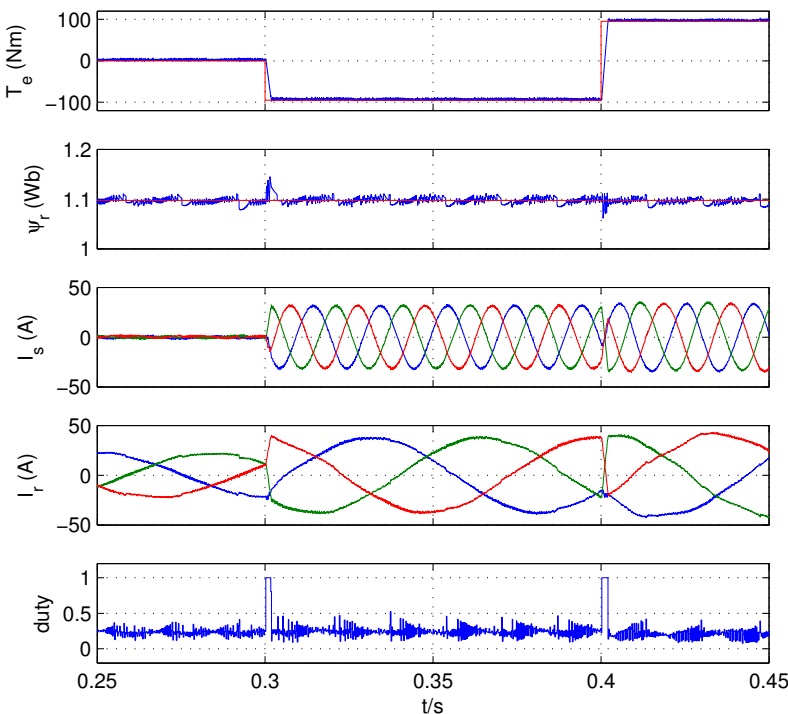

Fig. 11. Simulation results of the novel DTC with switching frequency reduction

TABLE IV

STEADY RESPONSES OF VARIOUS DTC CONSIDERING SWITCHING FREQUENCY REDUCTION

\begin{tabular}{ccccccc}
\hline method & $\begin{array}{c}f_{s} \\
(\mathrm{~Hz})\end{array}$ & $\begin{array}{l}f_{a v} \\
(\mathrm{~Hz})\end{array}$ & $\psi_{\text {rip }}(\mathrm{Wb})$ & $T_{\text {rip }}(\mathrm{Nm})$ & $\begin{array}{c}\text { THD } \\
\text { of } \boldsymbol{i}_{s}\end{array}$ & $\begin{array}{c}\text { THD } \\
\text { of } \boldsymbol{i}_{r}\end{array}$ \\
\hline $\begin{array}{c}\text { method I } \\
\text { using (11) }\end{array}$ & $5 \mathrm{k}$ & $1.45 \mathrm{k}$ & 0.0120 & 1.4965 & $2.25 \%$ & $3.75 \%$ \\
\hline $\begin{array}{r}\text { method II } \\
\text { using (12) }\end{array}$ & $4.8 \mathrm{k}$ & $1.44 \mathrm{k}$ & 0.0057 & 1.4166 & $1.68 \%$ & $1.92 \%$ \\
\hline
\end{tabular}

current and rotor current are only slightly increased, from $1.35 \%$ and $1.83 \%$ to $1.68 \%$ and $1.92 \%$, respectively, as shown in Tab. IV. The switching frequency reduction is universal for all duty based DTC method and the result for torque ripple minimization method is also summarized in Tab. IV. The flux ripple, THDs of stator and rotor currents for the novel method are much smaller than the results of ripple minimization method, exhibiting better performance. 

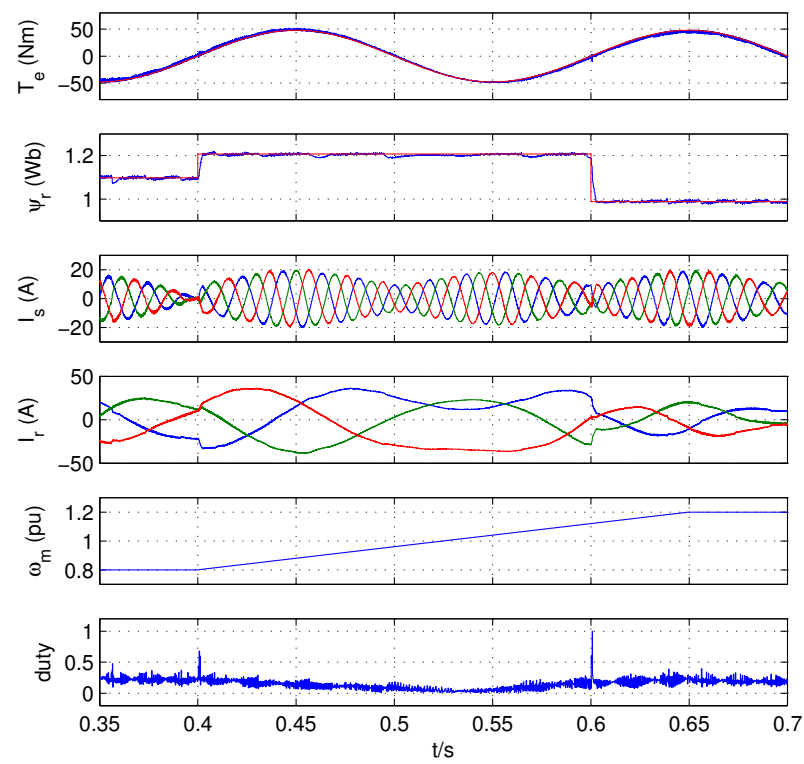

Fig. 12. Tracking behavior of the novel DTC with variable torque reference and rotor speed

\section{Tracking Behavior}

For wind energy applications, the DFIG is required to operate at variable rotor speed and the torque reference may also be variable, so it is necessary to test the performance of the novel DTC under this circumstance. Fig. 12 shows the result of the novel DTC method operating with variable speed from $0.8 \mathrm{pu}$ to $1.2 \mathrm{pu}$. The torque reference is generated by a $5 \mathrm{~Hz}$ sinusoidal waveform with an amplitude of $0.5 \mathrm{pu}$. The rotor flux reference is stepped from $1.03 \mathrm{pu}$ to $1.14 \mathrm{pu}$ at $0.4 \mathrm{~s}$ and then to $0.93 \mathrm{pu}$ at $0.6 \mathrm{~s}$. It is seen that the real torque can track the sinusoidal commanding torque very well under the condition of variable speed, validating the tracking capability of the novel method.

\section{Robustness Test}

Compared to other duty based DTC methods, the novel method eliminates the parameter dependence and greatly simplify the calculation of duty. Fig. 13 shows the result of the novel method with parameter mismatches. The test condition is the same as that in Fig. 6, except that the stator resistance, rotor resistance and mutual inductance used in the control system are all increased to $150 \%$ of their actual value. It is seen that there is very insignificant difference in the steady and dynamic responses compared to the result shown in Fig. 11, exhibiting strong robustness to the parameter variations.

\section{CONCLUSION}

This paper proposes a simple but effective method to reduce torque and flux ripples in DTC of DFIG. Different from the prior model based duty DTC, the novel method proposed in this paper eliminates the dependence on machine parameters. By exchanging the sequence of the active vector and the null vector appropriately, the switching frequency can be
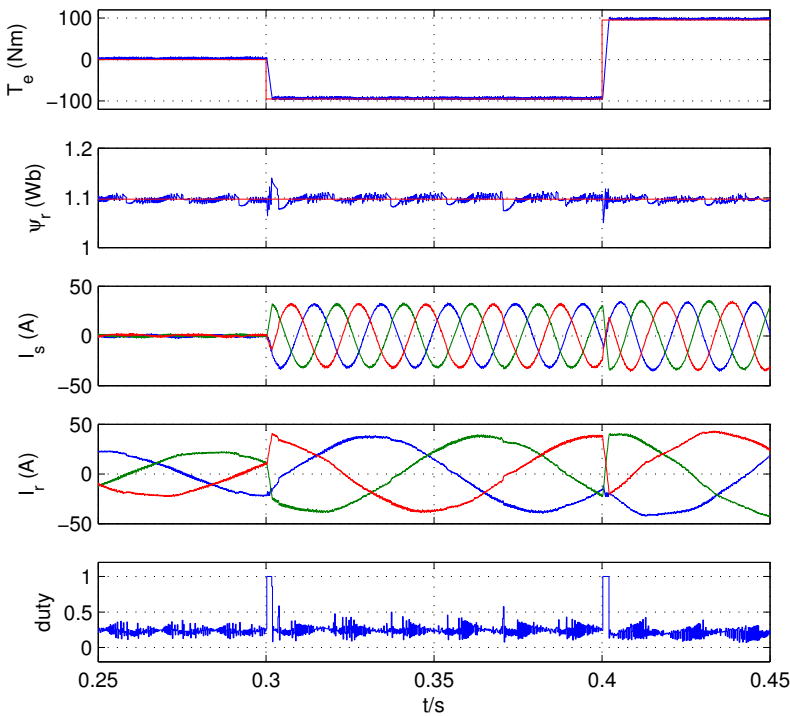

Fig. 13. Simulation results of the novel DTC with machine parameter mismatches $\left(R_{s}=1.5 R_{s}, R_{r}=1.5 R_{r}\right.$ and $\left.L_{m}=1.5 L_{m}\right)$

reduced up to $29 \%$ while the performance degradation is insignificant, which is favorable for the high power wind energy applications requiring low switching frequency. The novel DTC is compared with the torque ripple minimization DTC and shows smaller flux ripple and lower THDs of stator and rotor currents. The dynamic performance and torque ripple are similar. The effectiveness of the novel DTC is validated by the simulation results obtained from a $15 \mathrm{~kW}$ DFIG system.

\section{REFERENCES}

[1] Z. Chen, J. Guerrero, and F. Blaabjerg, "A review of the state of the art of power electronics for wind turbines," IEEE Trans. Power Electron., vol. 24, no. 8, pp. $1859-1875$, aug. 2009.

[2] Y. Zhang, J. Zhu, and J. Hu, "Model predictive direct torque control for grid synchronization of doubly fed induction generator," in Proc. IEEE Int. Electric Machines and Drives Conf. IEMDC '11, 2011, pp. 775-780.

[3] R. Pena, J. C. Clare, and G. M. Asher, "Doubly fed induction generator using back-to-back pwm converters and its application to variable-speed wind-energy generation," IEE Proceedings -Electric Power Applications, vol. 143, no. 3, pp. 231-241, 1996.

[4] Y. Zhang and J. Zhu, "Direct torque control of cascaded brushless doubly fed induction generator for wind energy applications," in Proc. IEEE Int Electric Machines and Drives Conf. IEMDC '11, 2011, pp. 751-756.

[5] K. Gokhale, D. Karraker, and S. Heikkila, "Controller for a wound rotor slip ring induction machine," USA Patent 6448 735B1, Jul. 22, 2002.

[6] Y. Zhang, J. Zhu, W. Xu, and Y. Guo, "A simple method to reduce torque ripple in direct torque-controlled permanent-magnet synchronous motor by using vectors with variable amplitude and angle," IEEE Trans. Ind. Electron., vol. 58, no. 7, pp. 2848-2859, 2011.

[7] J.-K. Kang and S.-K. Sul, "New direct torque control of induction motor for minimum torque ripple and constant switching frequency," IEEE Trans. Ind. Appl., vol. 35, no. 5, pp. 1076-1082, Sep./Oct. 1999.

[8] L. Romeral, A. Arias, E. Aldabas, and M. Jayne, "Novel direct torque control (DTC) scheme with fuzzy adaptive torque-ripple reduction," IEEE Trans. Ind. Electron., vol. 50, no. 3, pp. 487-492, June 2003.

[9] M. Pacas and J. Weber, "Predictive direct torque control for the PM synchronous machine," IEEE Trans. Ind. Electron., vol. 52, no. 5, pp. 1350 - 1356, oct. 2005.

[10] Y. Zhang and J. Zhu, "Direct torque control of permanent magnet synchronous motor with reduced torque ripple and commutation frequency," IEEE Trans. Power Electron., vol. 26, no. 1, pp. 235 -248, 2011. 